\title{
Correction: Estimating the Size of Key Populations in Kampala, Uganda: 3-Source Capture-Recapture Study
}

Reena H Doshi ${ }^{1,2}$, MPH, PhD; Kevin Apodaca ${ }^{1,3}$, MPH; Moses Ogwal ${ }^{4}$, BSc; Rommel Bain ${ }^{1}, \mathrm{PhD}$; Ermias Amene ${ }^{1}$, $\mathrm{PhD}$; Herbert Kiyingi ${ }^{5}, \mathrm{MD}$, MPH; George Aluzimbi ${ }^{5}, \mathrm{MPH}$; Geofrey Musinguzi ${ }^{4}, \mathrm{MPH}, \mathrm{PhD}$; David Serwadda ${ }^{4}$, MD, MPH, MSc; Anne F McIntyre ${ }^{1}$, MPH, PhD; Wolfgang Hladik ${ }^{1}$, MD, PhD

${ }^{1}$ Centers for Disease Control and Prevention, Center for Global Health, Division of Global HIV and TB, Atlanta, GA, United States

${ }^{2}$ Centers for Disease Control and Prevention, Epidemic Intelligence Service, Atlanta, GA, United States

${ }^{3}$ Public Health Institute, Oakland, CA, United States

${ }^{4}$ Makerere University, School of Public Health, Kampala, Uganda

${ }^{5}$ Centers for Disease Control and Prevention, Division of Global HIV and TB, Entebbe, Uganda

\section{Corresponding Author:}

Reena H Doshi, MPH, PhD

Centers for Disease Control and Prevention

Center for Global Health

Division of Global HIV and TB

1600 Clifton Road

Atlanta, GA, 30329

United States

Phone: 14702985583

Email: rdoshi@cdc.gov

\section{Related Article:}

Correction of: https://publichealth.jmir.org/2019/3/e12118/

(JMIR Public Health Surveill 2020;6(2):e19893) doi: 10.2196/19893

The article entitled "Estimating the Size of Key Populations in Kampala, Uganda: 3-Source Capture-Recapture Study" (JMIR Public Health Surveill 2019;5(3):e12118) published with a technical error that was introduced after proofreading.

The inline figure $\hat{\mathrm{N}}$ was incorrectly inserted as Figure 4. Figure 4 has now been removed from the manuscript.
The correction will appear in the online version of the paper on the JMIR website on May 12, together with the publication of this correction notice. Because this was made after submission to PubMed, PubMed Central, and other full-text repositories, the corrected article has also been resubmitted to those repositories.

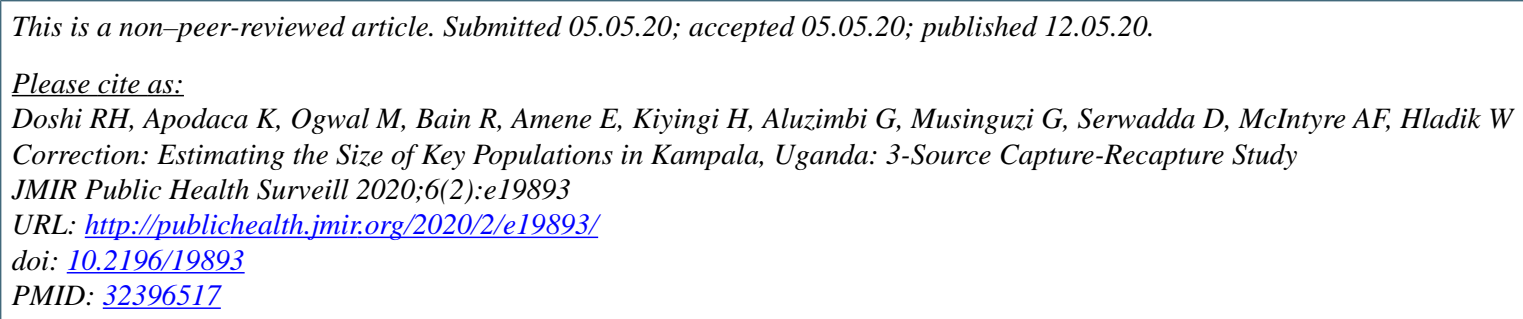

CReena H Doshi, Kevin Apodaca, Moses Ogwal, Rommel Bain, Ermias Amene, Herbert Kiyingi, George Aluzimbi, Geofrey Musinguzi, David Serwadda, Anne F McIntyre, Wolfgang Hladik. Originally published in JMIR Public Health and Surveillance (http://publichealth.jmir.org), 12.05.2020. This is an open-access article distributed under the terms of the Creative Commons Attribution License (https://creativecommons.org/licenses/by/4.0/), which permits unrestricted use, distribution, and reproduction in any medium, provided the original work, first published in JMIR Public Health and Surveillance, is properly cited. The complete 
bibliographic information, a link to the original publication on http://publichealth.jmir.org, as well as this copyright and license information must be included. 